International Journal of Engineering \&Technology, $7(4.24)(2018) 142-147$
International Journal of Engineering \& Technology
Website: www.sciencepubco.com/index.php/IJET
Research paper

\title{
A Three Phase Matlab Simulink Model of IEEE 57 Bus Power System Network
}

\author{
VeeraBhadra Chary.Gade ${ }^{1 *}$, Mercy Rosalin.Kotapuri ${ }^{2}$ \\ ${ }^{I}$ Research Scholar, Department of Electrical and Electronics Engineering, Vignan's Foundation for Science Technology \& Research, \\ Vadlamudi, A.P., India. \\ ${ }^{2}$ Associate Professor, Department of Electrical and Electronics Engineering, Vignan's Foundation for Science Technology \& Research \\ , Vadlamudi, A.P., India \\ *Corresponding author E-mail:vbcharyg@gmail.com
}

\begin{abstract}
The Electrical power system, field engineers always strive to design a Real time power system model to anticipate the practical outcomes. The simulation software not only fixes the changes in power system, but also trying to perceive the potential impact of power system before construction. A realistic model of the power system is very essential for the future and present operations. Present, this paper makes center of attention on designing of 3-phase power system network of IEEE 57 bus power system network within the Matlab Simulink module. It supports GUI (Graphical User Interface) based models of power system components, which are used to design a dynamic model of the power system. The present design is based on the test case data and the one line diagram; so that the three-phase model is equivalent to single phase one line diagram. The simulation of this model allows for verification of voltage, current, active power and reactive power of each bus and variation of those parameters with respect to time domain waveform. The present model is also useful for learning the operation of the power system network under Steady state, Transient state and Dynamic state with the application of FACTS, Fuzzy, and ANN etc.
\end{abstract}

Keywords: ANN, Dynamic model, FACTS, Fuzzy, IEEE 57 bus.

\section{Introduction}

The advancement in power system modeling and simulation are impressed by the engineers to predict the operation of the power system. These models are most essential for economic design and planning of very large infrastructure power system network. Early days the power system modeling is all about the mathematical equations and with added rules and become digital after the computer era. However, the real time modeling has an importance as well as limitations [1]. Now a day, extraordinary computer tools available to model a power system network in every aspect. Therefore, a single simulation can connect hundreds of transmission lines to corresponding generating stations, including every component which is supporting the system. There are various real time technologies in power and energy systems. In power system application industry, only few software's useful for simulation of big power systems remaining either for small systems or for design real time controllers. The real time simulations used for both academia and industry for analysis, designing and testing of power system and its components. There are various Digital Real Time Simulations (DRTS) using nowadays, based on application domain DRTS classified as Fully Digital Real Time simulation (FDRTS), and Hardware In the Loop (HIL). The first type of simulation consists Model In the Loop (MIL), Software In the Loop (SIL) and Processor In the Loop (PIL), these are consisting of protection, control and equipment in the model not controlled by external input or output. The second type HIL model is simulated by external signals from ADC, DAC, signal conditioners, Filters etc. [2].

For the last two decades Math Works.Inc has been playing a major role in the power system field of education and research. Therefore, it is one of the better choice to understand power system, the Matlab has key attributes like graphical tool platform, Programing platform, graph plotting capabilities. It has various tool packages and also allows new packaging tools like Electro Magnetic Transient Pregame (EMTP), Mat Power, Power System Toolbox (PST), Power Analysis Toolbox (PAT), Sim Power Systems (SPS), Power System Analysis Toolbox (PSAT) etc. [3]-[7].The analysis of dynamic systems, modeling and simulation Simulink uses various featured toolboxes such as ANN, Fuzzy, Wavelets, DSP, Prony etc. Simulink blocks can also work with integration of $\mathrm{C}, \mathrm{C}^{++}$, Fortan and Matlab code. Therefore with these features matlab became one best choice for power system research and analysis [8]-[10]. The TABLE 1 shows the approximation of various software package tools with its available features.

Multiple number papers address by the Matlab Simulink in power system simulation. In the power quality study a discrete flicker meter model of IEC-6100-4-15 designed inSimulink for $\mathrm{m}$ 
Table .1: Comparison of the Power System Simulation Packages

\begin{tabular}{|c|c|c|c|c|c|c|c|c|}
\hline Software & $\begin{array}{c}\text { Graphical Net- } \\
\text { work Editor }\end{array}$ & $\begin{array}{c}\text { Graphical } \\
\text { User Inter- } \\
\text { face }\end{array}$ & $\begin{array}{l}\text { Time Domain } \\
\text { Simulation }\end{array}$ & $\begin{array}{c}\text { Small Signal } \\
\text { Stability }\end{array}$ & $\begin{array}{l}\text { Electro Magnet- } \\
\text { ic Transient }\end{array}$ & $\begin{array}{l}\text { Power } \\
\text { Flow }\end{array}$ & $\begin{array}{c}\text { Optimal } \\
\text { Power Flow }\end{array}$ & $\begin{array}{c}\text { Continue } \\
\text { Power Flow }\end{array}$ \\
\hline VST & & $\sqrt{ }$ & $\sqrt{ }$ & $\sqrt{ }$ & & $\sqrt{ }$ & & $\sqrt{ }$ \\
\hline SPS & $\sqrt{ }$ & $\sqrt{ }$ & $\sqrt{ }$ & $\sqrt{ }$ & $\sqrt{ }$ & $\sqrt{ }$ & & \\
\hline $\begin{array}{c}\text { Mat } \\
\text { Power }\end{array}$ & & & & & & $\sqrt{ }$ & $\sqrt{ }$ & \\
\hline EMTP & $\sqrt{ }$ & $\sqrt{ }$ & $\sqrt{ }$ & & $\sqrt{ }$ & & & \\
\hline PST & & & $\sqrt{ }$ & $\sqrt{ }$ & & $\sqrt{ }$ & & $\sqrt{ }$ \\
\hline PAT & $\sqrt{ }$ & & $\sqrt{ }$ & $\sqrt{ }$ & & $\sqrt{ }$ & & \\
\hline PSAT & $\sqrt{ }$ & $\sqrt{ }$ & $\sqrt{ }$ & $\sqrt{ }$ & & $\sqrt{ }$ & $\sqrt{ }$ & $\sqrt{ }$ \\
\hline
\end{tabular}

-easuringflickers, the function of this meter is same as the standardized model [11]. A Simulink based education on illustrating the stability, control and dynamics given a positive response from the Learners which give a hands-on experience gain with the simulations. During this study, explanation of power system behavior with respect to mathematical derivations, it allows comments and identical similarities [12].The simulation of power electronic converters in Matlab is very important in assessment, modeling and analysis of nonlinear state space, power electronic converters and their controllers for understanding the dynamic behavior with respect to theoretical modeling. These converters simulation time is very few mille seconds, therefore the convergence problem omitted [13]. In a grid connected power system network to locate and positioning of pv system at low voltage locations is a challenge to the engineers and it is very essential to simulate the accurate models in computer. A well designed Simulink model establishes the development of pv array model, MPPT controllers and power electronic converters denote the actual behavior of the grid system[14]. If the total system compared with load flow methods power transfer in the system through the various components assessed to design accurate grid connected system [15]. The wind power generation system consists of the wind, mechanical and electrical equipment's; hence it is very required to design a detailed Simulink model to assess the combined operational performance of the model by the simulation results [16]. However, to analyze performance of such systems by the series compensation, which reduces Sub Synchronous Resonance (SSR) so as to protect the turbine shaft, analyze the impact of different parameters, dynamic performance of a model and assessment of results with respect to time [17].

The primary objective of this paper is to design a realistic model of IEEE 57 bus power system network for real time analysis of the network in future. A balanced 3-phase power system network modeled in the Matlab Simulink platform. The Transmission line, synchronous generators, loads and transformers all are modularized conventional models, which can easily access from matlab / simscape / power system library. These models can easily modify the network, according to the requirement in modeling and very easy to design. The simulation model is a single phase equivalent three phase power system network, therefore the total system as per the single line block diagram model. The numerical simulation results well suited for the exertion of the network for future power system application analysis and in real time projects. In this paper the simulation results useful to exercise voltage, angle, active power and reactive power at all the buses. The present model is very accurate and effective, useful for designing any type of power system mode for evaluation.

This paper organized as per the following sections; power system structure and components well narrated in Section II. The simulation results in the form of tables described in Section III. A brief analysis and discussions in Section IV. The provision of extension of work for various types of applications in V.

\section{Power System Structure And Components}

The Matlab, Simulink platform was popularly known for designing any type of dynamic power system network. The powerful motivation is due to the difficulties in mathematical equation form modeling. The Simulink avails standard models of power system components and various control tool boxes which enable to automatic use of components. However, the present versions have simscape, it contains most generally used voltage sources, electrical machines, power lines, transformers, loads, measurements, etc. With the account of latest improvements the simulation of power system networks very useful to design identical models of power system networks. This section describes about power system model and its components such as Generators, Transmission lines, and loads.

\subsection{Power System Model}

Originally the IEEE 57 bus power system is an American electrical power system which is located in the Midwestern in 1960's. The data of this network were recognized by the IEEE organization in 1993, which is entered by the Rich Christi of the University of Washington [18]. As shown in Fig. 1 this network has 63 transmission lines, 7 generators, 42 loads and 17 tap setting transformer. According to the entered data the transmission line does not possess any active and reactive power limits. The 3-phase balanced Simulink modelling process as follows: Review the power system structure and original data for assessment of the number of components required and rating, collect all the components from the simscapes power system library, connect the components as per the reference block diagram. This power system consists of two sections, first one is Transmission section and second one is Distribution section. The first section consists of generators, 1 to 17 buses of voltage of $138 \mathrm{Kv}$ (line-line), and Tap setting transformers. The second section consists of 18 to 57 buses of voltage of $69 \mathrm{Kv}$ (line-line) and distribution loads.

\section{2. $\pi$-Model Transmission Line}

In the modelling, all the transmission lines are designed as 3-phase pi model transmission lines, the Fig. 2 showing the several cascaded per km section linear transmission lines shown with respect to Phase A. The line lengths in the models are lying between 1.5 $\mathrm{km}$ to $117 \mathrm{~km}$. In the line resistance (Rs), inductance (Ls) and shunt capacitance (Csh) distributed along line, therefore the approximate length of line acquire by cascading No.of pi sections. The linear pi model lines in the Simulink is also useful for computing the state space model and allow to design any length of line by simply entering the length of line in $\mathrm{km}$. The line parameters chosen as per IEEE standard 138 / $69 \mathrm{Kv}$ transmission line parameters tables and the length of lines computed to the power system model. The lines in this model behave as real pi type transmission lines. 


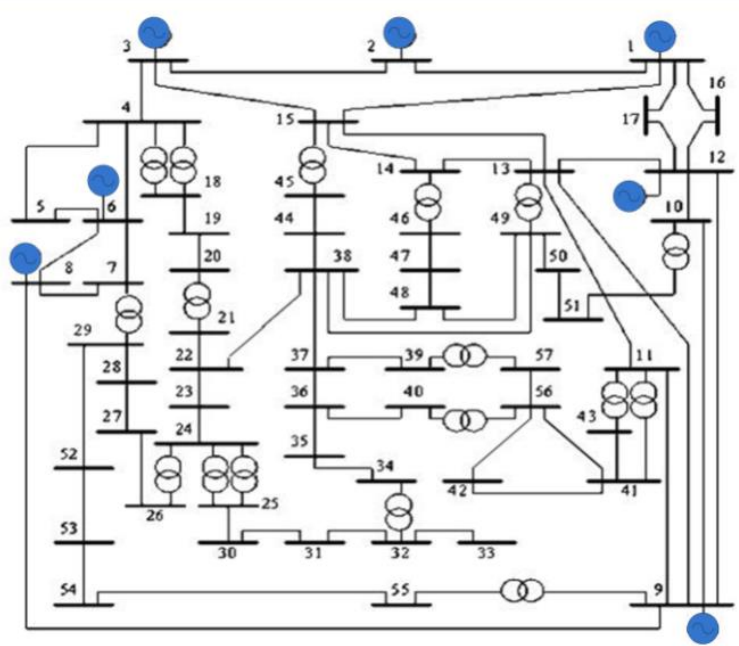

Fig. 1. Single Line block diagrm of IEEE 57 bus power system structure

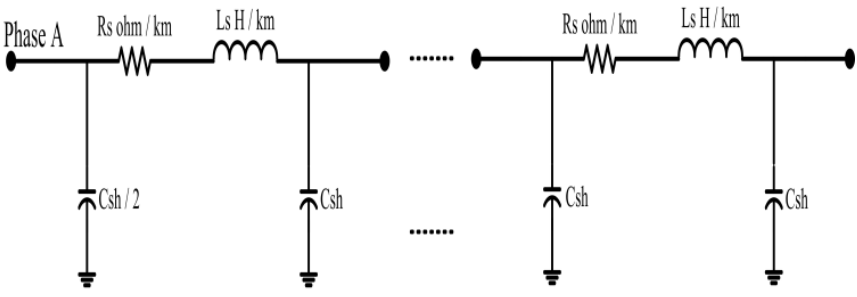

Fig. 2. Distributed per kilometer Pi sections linear transmission line model

\subsection{Three Phase Source Model}

The model consists of 7 generating stations, a constant voltage source block in simscape used as generating station. The Fig. 3 shows the circuit diagram of constant voltage source block in simscape. Since, it is a balanced constant voltage source model, all the phase voltages are equal in magnitude and phase. It is a $\mathrm{Y}$ connected generator model, thereforethe zero sequence component voltages / currents pass to the ground and avoid lower order harmonics. The block consists of internal parameters such as resistance (Ras), Inductance (Las) connected series to the Single phase voltage source. The short circuiting capacity of this source depending on the ratio of the internal inductive reactance to the internal resistance i.e. $\mathrm{X} / \mathrm{R}$ ratio.

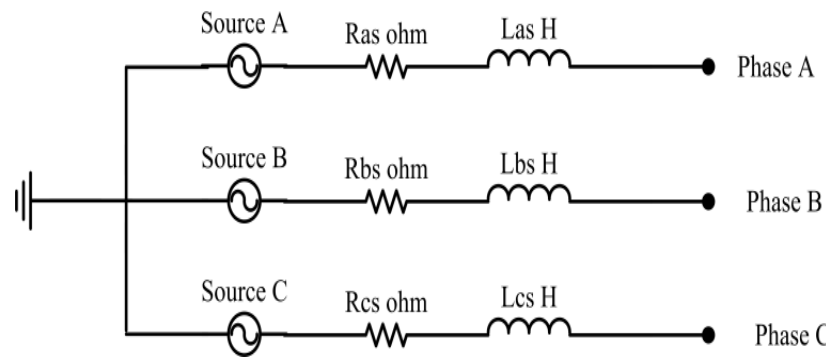

Fig. 3. 3-phase constant voltage source model block diagram

\subsection{Three Phase Load Model}

The Fig. 4 representing a simple 3-phase balanced star (Y) connected load with a combination of elements such as resistance (Ral), and Inductance (Lal) in series to each phase. Since all the loads are active and reactive loads in power system, this load model consumes active power $(\mathrm{P})$ and reactive power $(\mathrm{Q})$ in power system. The load block in Simulink allows either balanced or unbalanced distribution of load powers. The Present model, all the load blocks are modeled as balanced loads, therefor total active and reactive powers equally shared among the three phases which leads to constant impedance offers each phase of the load. In this paper all the loads consider as constant PQ loads.

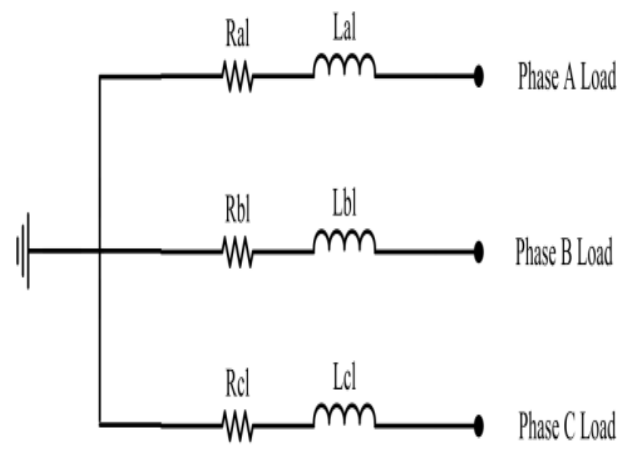

Fig. 4. Three Phase Y-connected Load model

The modeling procedure of the power system network as follows:

- $\quad$ Use the Single-Line diagram of IEEE 57 bus test case system with data for Simulink modeling.

- $\quad$ Drag the required components from simscape library such as transmission lines, voltage sources, transmformers and loads.

- Connect the components as per the power system diagram. Feed the required technical data in components.

- Save the Simulink file, run the simulations to verify the voltages, phase angles, active power and reactive power.

- Compare the results with the standard test case system data.

\section{Results}

The Steady State and Time domain simulations were performed on the Simulink model for a time period of $1 \mathrm{~s}$ to find power system constraints. The two simulations were conducted in Matlab / Simulink environment to evaluate the existing performance of model. Since the network is balanced, the simulation results tabulated for Phase A. The steady state simulation conducted to determine voltage and currents in first phase at all the buses. However, in reaming phases also has equal in magnitude and shifted by $120^{\circ}$ with respect to the each other phase. Therefore, these results verified with test case results. The time domain simulation conducted to figure out the wave shape of three phase voltage at the buses and compute the instantaneous active powers and Reactive powers at the buses. The powers at the buses reckon total power pass through the connected transmission lines, thus the capability of the bus can be assessed. All the results are tabulated without loads and with loads are shown in TABLE II, it is very useful to examine the parameters change at all the buses from no-load case to Full load case. The results acquired after the simulations are useful to examine the performance of model with the actual power system. 
Table .2: Voltage $\left(\mathrm{V}_{\mathrm{A}}\right)$ and Current $\left(\mathrm{I}_{\mathrm{A}}\right)$ with corresponding phase Angle, the Active Power $\left(\mathrm{P}_{\mathrm{ABC}}\right.$ and Reactive Power $\left(\mathrm{Q}_{\mathrm{ABC}}\right)$ at the bus.)

\begin{tabular}{|c|c|c|c|c|c|c|c|c|c|c|c|c|}
\hline \multirow{3}{*}{ Bus no. } & \multicolumn{6}{|c|}{ With Loads } & \multicolumn{6}{|c|}{ Without Loads } \\
\hline & \multicolumn{4}{|c|}{ Phase A } & \multicolumn{2}{|c|}{ 3-Phase Power } & \multicolumn{4}{|c|}{ Phase A } & \multicolumn{2}{|c|}{ 3-Phase Power } \\
\hline & $\begin{array}{c}\mathbf{V}_{\mathbf{A}} \\
(\mathbf{r m s}) \\
\mathbf{K v}\end{array}$ & $\begin{array}{l}\text { Angle } \\
\text { (deg.) }\end{array}$ & $\begin{array}{c}\mathbf{I}_{\mathbf{A}} \\
(\mathbf{r m s}) \\
\text { amps }\end{array}$ & $\begin{array}{l}\text { Angle } \\
\text { (deg.) }\end{array}$ & $\begin{array}{l}\mathbf{P}_{\mathrm{ABC}} \\
\mathbf{M w}\end{array}$ & $\begin{array}{l}\mathbf{Q}_{\mathrm{ABC}} \\
\text { Mvar }\end{array}$ & $\begin{array}{c}\mathbf{V}_{\mathbf{A}} \\
(\mathbf{r m s}) \\
\mathbf{K v}\end{array}$ & $\begin{array}{l}\text { Angle } \\
\text { (deg.) }\end{array}$ & $\begin{array}{c}\mathbf{I}_{\mathbf{A}} \\
(\mathbf{r m s}) \\
\text { amps }\end{array}$ & $\begin{array}{l}\text { Angle } \\
\text { (deg.) }\end{array}$ & $\mathbf{P}_{\mathrm{ABC}} \mathbf{M w}$ & $\begin{array}{c}\mathbf{Q}_{\mathrm{ABC}} \\
\text { Mvar }\end{array}$ \\
\hline 1 & 79.635 & -0.07 & 532.66 & -13.52 & 123.7 & 29.44 & 79.669 & -163.13 & 46.67 & -73.44 & 0.148 & -11 \\
\hline 2 & 79.604 & 0 & 351.62 & -84.36 & 8.909 & 83.52 & 79.52 & -163.1 & 46.63 & -73.43 & 0.152 & -10.97 \\
\hline 3 & 79.621 & -0.07 & 550.62 & -20.61 & 123 & 45.85 & 79.73 & -163.14 & 46.69 & -73.44 & 0.146 & -11.01 \\
\hline 4 & 79.217 & -0.63 & 122.12 & -14.7 & 28.12 & 7.008 & 79.872 & -163.17 & 18.63 & -73.51 & 0.0604 & -4.401 \\
\hline 5 & 79.34 & -0.56 & 5.35 & -149.48 & -1.098 & 0.661 & 79.893 & -163.17 & 5.76 & 106.64 & 0.0156 & 1.36 \\
\hline 6 & 79.653 & -0.07 & 500.04 & -3.86 & 119.2 & 7.815 & 79.784 & -163.15 & 46.71 & -73.44 & 0.1449 & -11.02 \\
\hline 7 & 78.645 & -1.32 & 101.32 & -19.69 & 22.64 & 7.49 & 79.951 & -163.19 & 3.56 & -76.07 & 0.0502 & -0.841 \\
\hline 8 & 79.629 & -0.11 & 771.91 & -9.04 & 182 & 28.51 & 79.841 & -163.16 & 46.73 & -73.44 & 0.143 & -11.04 \\
\hline 9 & 79.598 & -0.13 & 977.59 & -14.89 & 225 & 59.11 & 80.088 & -163.21 & 46.8 & -73.45 & 0.136 & -11.09 \\
\hline 10 & 78.553 & -1.76 & 93.15 & -17.32 & 21.08 & 5.847 & 80.424 & -163.27 & 3.72 & -73.13 & 0.002 & -0.885 \\
\hline 11 & 78.16 & -1.84 & 49.19 & 123.99 & -6.813 & -9.315 & 80.373 & -163.26 & 6.36 & -70.42 & -0.08 & -1.51 \\
\hline 12 & 79.569 & -0.29 & 2101.15 & -6.56 & 498.3 & 54.48 & 80.182 & -163.22 & 46.83 & -73.46 & 0.134 & -11.11 \\
\hline 13 & 77.455 & -2.03 & 80.96 & 150.54 & -16.67 & -8.611 & 80.232 & -163.24 & 6.11 & -70.81 & 0.058 & -14.48 \\
\hline 14 & 76.983 & -2.41 & 154.14 & -38.51 & 28.77 & 20.87 & 80.163 & -163.23 & 9.38 & -75.19 & 0.1136 & -2.224 \\
\hline 15 & 78.233 & -1.63 & 246.62 & -20.58 & 54.75 & 18.39 & 80.038 & -163.2 & 27.94 & -73.65 & 0.1079 & -6.617 \\
\hline 16 & 79.087 & -1.66 & 56.9 & -11.13 & 13.29 & 2.22 & 80.196 & -163.23 & 3.17 & -73.87 & 0.015 & -0.75 \\
\hline 17 & 78.781 & -1.71 & 115.1 & -10.11 & 26.87 & 3.957 & 80.046 & -163.2 & 12.95 & -73.37 & 0.034 & -3.067 \\
\hline 18 & 40.657 & -1.29 & 304.59 & -19.62 & 35.19 & 11.62 & 42.279 & -163.23 & 13.77 & -73.73 & 0.0285 & -1.722 \\
\hline 19 & 39.696 & -3.77 & 60.32 & -21.36 & 6.831 & 2.157 & 42.579 & -163.34 & 4.71 & -74.6 & 0.017 & -0.5926 \\
\hline 20 & 39.216 & -4.55 & 35.24 & -35.56 & 3.538 & 2.124 & 42.616 & -163.35 & 1.06 & 112.21 & 0.011 & 0.133 \\
\hline 21 & 40.894 & -4.57 & 2.39 & -27.11 & 0.26 & 0.107 & 44.379 & -163.35 & 0.83 & 100.6 & -0.0130 & 0.1086 \\
\hline 22 & 40.882 & -4.58 & 3.27 & -52.06 & 0.259 & 0.29 & 44.37 & -163.35 & 2.45 & 104.6 & -0.147 & 0.3211 \\
\hline 23 & 40.839 & -4.67 & 107.46 & -23.36 & 12.44 & 4.191 & 44.383 & -163.35 & 17.56 & -71.03 & -0.082 & -2.303 \\
\hline 24 & 40.477 & -5.42 & 51.63 & -27.05 & 5.81 & 2.297 & 44.577 & -163.4 & 14.02 & -70.44 & -0.088 & -1.845 \\
\hline 25 & 40.395 & -5.67 & 120.59 & -28.24 & 13.46 & 5.561 & 45.71 & -163.4 & 14.96 & -71.5 & -0.059 & -2.021 \\
\hline 26 & 38.87 & -5.26 & 95.75 & -34.59 & 9.711 & 5.433 & 42.691 & -163.35 & 0.87 & -119.56 & -0.081 & -0.076 \\
\hline 27 & 39.68 & -4 & 167.54 & -21.29 & 19 & 5.88 & 42.665 & -163.33 & 4.03 & -82.35 & 0.084 & -0.502 \\
\hline 28 & 40.091 & -3.04 & 210.09 & -22.69 & 23.76 & 8.44 & 42.645 & -163.32 & 5.29 & -80.19 & -0.085 & -0.662 \\
\hline 29 & 40.428 & -2.33 & 456.93 & -18.32 & 53.15 & 15.16 & 42.629 & -163.31 & 15.95 & -75.61 & -0.097 & -2.01 \\
\hline 30 & 40.063 & -6.39 & 61.81 & -26.2 & 6.969 & 2.492 & 45.841 & -163.43 & 12.08 & -71.04 & -0.0643 & -1.636 \\
\hline 31 & 39.692 & -7.27 & 30.28 & -29.68 & 3.32 & 1.363 & 46.045 & -163.48 & 4.98 & -67.59 & -0.073 & -0.673 \\
\hline 32 & 40.166 & -6.33 & 20.54 & 163.68 & -2.43 & -4.202 & 46.033 & -163.45 & 5.91 & 101.58 & -0.084 & 0.802 \\
\hline 33 & 40.125 & -6.4 & 35.81 & -32.96 & 3.841 & 1.913 & 46.034 & -163.45 & 0 & 0 & 0 & 0 \\
\hline 34 & 39.211 & -6.17 & 83.28 & -31.03 & 8.873 & 4.087 & 44.39 & -163.38 & 6.42 & -79.82 & 0.11 & -0.838 \\
\hline 35 & 39.411 & -5.81 & 138.39 & -31.21 & 14.75 & 6.966 & 44.365 & -163.36 & 7.49 & -78.89 & 0.1121 & -0.979 \\
\hline 36 & 39.641 & -5.4 & 138.11 & 149.04 & 14.78 & -7.033 & 44.346 & -163.36 & 8.23 & 101.6 & -0.113 & 1.076 \\
\hline 37 & 39.968 & -5.22 & 232.78 & -50.66 & 19.64 & 19.78 & 44.331 & -163.35 & 3.05 & 147.47 & 0.296 & 0.299 \\
\hline 38 & 40.962 & -4.4 & 118.04 & 22.05 & 12.8 & -6.461 & 44.341 & -163.34 & 24.09 & -72.94 & -0.0233 & -3.159 \\
\hline 39 & 39.933 & -5.35 & 51.09 & -13.12 & 6.041 & 0.823 & 44.309 & -163.35 & 12.22 & 112.62 & 0.181 & 1.59 \\
\hline
\end{tabular}




\begin{tabular}{|c|c|c|c|c|c|c|c|c|c|c|c|c|}
\hline 40 & 39.426 & -5.29 & 101.02 & -101.86 & -1.258 & 11.83 & 44.347 & -163.36 & 0.03 & 109.07 & 0 & 0.003 \\
\hline 41 & 40.894 & -2.33 & 87.78 & 178.18 & -10.71 & 0.114 & 43.747 & -163.3 & 15.31 & 108.39 & 0.054 & 1.979 \\
\hline 42 & 40.528 & -4.4 & 45.94 & -130.9 & -3.279 & 4.47 & 43.965 & -163.36 & 10.5 & 109.17 & 0.06131 & 1.363 \\
\hline 43 & 40.789 & -1.92 & 29.95 & 2.85 & 3.632 & -0.309 & 43.443 & -163.23 & 18.1 & -70.63 & -0.1 & -2.32 \\
\hline 44 & 40.889 & -3.94 & 212.43 & 6.1 & 25.49 & -4.54 & 44.272 & -163.32 & 24.9 & -72.95 & -0.021 & -3.259 \\
\hline 45 & 40.996 & -2.13 & 212.68 & 6.52 & 25.7 & -3.95 & 44.12 & -163.27 & 26.61 & -72.98 & -0.0164 & -3.471 \\
\hline 46 & 42.392 & -3.09 & 331.28 & -37.71 & 34.67 & 23.8 & 44.36 & -163.34 & 1.98 & 133.43 & 0.014 & 0.23 \\
\hline 47 & 41.568 & -4.1 & 331.78 & -37.83 & 34.4 & 22.85 & 44.352 & -163.34 & 2.85 & 124.9 & 0.142 & 0.539 \\
\hline 48 & 41.471 & -4.09 & 84.91 & -82.82 & 2.153 & 10.31 & 44.348 & -163.34 & 3.16 & 123.07 & 0.142 & 0.396 \\
\hline 49 & 42.296 & -3.25 & 625.56 & -40.84 & 62.92 & 48.17 & 44.341 & -163.33 & 2.76 & 123.64 & 0.132 & 0.344 \\
\hline 50 & 41.697 & -3.78 & 113.89 & -47.01 & 10.39 & 9.708 & 44.297 & -163.32 & 7.94 & 107.78 & 0.0135 & 1.041 \\
\hline 51 & 42.105 & -2.39 & 101.51 & 169.95 & -12.64 & -1.676 & 44.198 & -163.29 & 10.97 & 107.48 & 0.009 & 1.435 \\
\hline 52 & 39.928 & -3.48 & 103.56 & -21.37 & 11.74 & 3.775 & 42.706 & -163.34 & 7.42 & -73.35 & 0.007 & -0.937 \\
\hline 53 & 39.796 & -3.84 & 59.28 & -17.72 & 6.823 & 1.677 & 42.738 & -163.35 & 6.11 & -73.35 & 0.006 & -0.7726 \\
\hline 54 & 40.861 & -2.4 & 128.17 & 144.93 & -13.22 & -8.429 & 42.789 & -163.37 & 3.02 & -73.34 & 0.002 & -0.381 \\
\hline 55 & 42.128 & -0.6 & 163.05 & 148.91 & -17.75 & -10.39 & 42.805 & -163.37 & 0 & 79.36 & 0 & 0 \\
\hline 56 & 41.002 & -5.25 & 22.11 & 130.66 & -1.961 & -1.88 & 44.103 & -163.4 & 15.34 & 110.61 & 0.15 & 1.99 \\
\hline 57 & 40.742 & -5.45 & 41.43 & -3.33 & 5.034 & -0.1908 & 44.273 & 163.43 & 11.77 & 111.84 & 0.1563 & 1.533 \\
\hline
\end{tabular}

\section{Conclusion}

A Matlab based balanced 3-phase Simulink model of single phase equivalent IEEE 57 bus power system network designed in this paper. The current model is approximately identical to the original power system structure. The performance of the power system is as a real time system, the results show the effective performance of the model. The modeling activity in this paper made to learn many designing and operational constraints which were leading to evaluative observations such as; the powers drawn at the buses and power drawn by the loads are shown the accuracy of modeling and the phase sequence of the bus voltage waveforms show the correctness of shifting of voltage waveforms. The observations and results disclose whether the model is working properly as per expectation or not.

\section{Future Scope}

The simpower systems Simulink platform has very flexible for designing any type of power system network. The power system network designed in this paper is very convenient for conducting of power flow study, dynamic study of power system with power system stabilizers, transient analysis by conducting symmetrical and unsymmetrical fault tests. Present days, non-conventional energy power plants like solar, wind plays major role in the distribution system. Therefore, this model is very useful to study the characteristics of these power plants under various conditions. The Power quality can study by using various FACTS devices. This model can allow the various application tools for power system analysis like Fuzzy logic, Neural Network, Digital Signal Processing, wavelets, prony analysis etc.

\section{References}

[1] Andrew Isaacs, "Simulation Technology: The Evolution of Power System Modeling," IEEE POWER \& ENERGY MAGZINE, vol. 15, no. 4, pp 88 - 102, June. 2017.

[2] IEEE PES Task Force and T. STRASSER "Real-Time Simulation Technologies for Power Systems Design, Testing, and Analysis,' IEEE POWER \& ENERGY TECHNOLOGY, vol. 2, no. 2, pp 63 73 , Jun. 2015
[3] Federico Milano," An Open Source Power System Analysis Toolbox," IEEE TRANSACTIONS ON POWER SYSTEMS, vol. 2, no. 3, pp 1199 - 1206, Aug. 2005.

[4] R. D. Zimmerman, C. E. Murrillo-Sánchez, and D. Gan (2005)Matpower, Version 3.0.0, User's Manual. Power System EngineeringResearch Center, Cornell Univ., Ithaca, NY.[Online] Available:http://www.pserc.cornell.edu/matpower/matpower.html

[5] G. Sybille. (2004, Oct.) SimPowerSystems User's Guide, Version 4.Published under sublicense from Hydro-Québec, and The MathWorks,Inc.. [Online] Available at: http://www.mathworks.com.

[6] K. Schoder,A. Hasanovic',A. Feliachi, and A. Hasanovic', "PAT: a poweranalysis toolbox for MATLAB/Simulink," IEEE Trans. Power Syst., vol.18, no. 1, pp. 42-47, Feb. 2003.

[7] F. Milano. (2002) PSAT, Matlab-Based Power System AnalysisToolbox. [Online] Available at: http://thunderbox.uwaterloo.ca/ fmilano

[8] Karl Schoder, AmerHasanovic', Ali Feliachi, and AzraHasanovic," PAT: A Power Analysis Toolbox forMATLAB/Simulink," IEEE TRANSACTIONS ON POWER SYSTEMS, vol. 18, no. 1, pp42 - 47, Feb. 2003

[9] T. Hiyama and A. Ueno, "Development of real time power system simulator in MATLAB/Simulink environment," in IEEE POWER ENGINEERINGSOCIETY, Summer Meeting, Seattle, WA, July $16-20,2000$

[10] Hydro-Quebec and TEQSIM International, "Power system blockset for use with Simulink," The Mathworks Inc., Natick, MA, 2001.

[11] Leonard W. White, and Subhashish Bhattacharya," A Discrete Matlab-Simulink Flickermeter Model forPower Quality Studies," IEEE TRANSACTIONS ON INSTRUMENTATION AND MEASUREMENT, vol. 59, no. 3, pp 527 - 533, Mar. 2010.

[12] Costas D. Vournas, Emmanuel G. Potamianakis, Cédric Moors, andThierry Van Cutsem," An Educational Simulation Tool for Power SystemControl and Stability," IEEE TRANSACTIONS ON POWER SYSTEMS, vol. 19, no. 1, pp 48 - 55, Feb. 2004

[13] VitorFernãoPires, ,and José Fernando A. Silva," Teaching Nonlinear Modeling, Simulation, andControl of Electronic Power Converters UsingMATLAB/SIMULINK," IEEE TRANSACTIONS ON EDUCATION, vol. 45, no. 3, pp 253 - 261, Aug. 2002.

[14] Michael E. Ropp, and Sigifredo Gonzalez,“ Development of a MATLAB/Simulink Model of aSingle-Phase Grid-Connected Photovoltaic System," IEEE TRANSACTIONS ON ENERGY CONVERSION, vol. 24, no. 1, pp 195 - 202, Feb. 2009

[15] Antonio Cataliotti, ValentinaCosentino, Dario Di Cara, PierlucaRussotto, Enrico Telaretti,and Giovanni Tinè, “" An Innovative Measurement Approach for LoadFlow Analysis in MV Smar Grids," IEEE TRANSACTIONS ON SMART GRID, vol. 7, no. 2, pp 889 - 896, Mar. 2016. 
[16] RoohollahFadaeinedjad, MehrdadMoallem, and Gerry Moschopoulos, "“ Simulation of a Wind Turbine With Doubly FedInduction Generator by FAST and Simulink," IEEE TRANSACTIONS ENERGY CONVERSION, vol. 23, no. 2, pp690 - 700, Jun. 2008.

[17] Lingling Fan, Chanxia Zhu, Zhixin Miao, and Minqiang $\mathrm{Hu}$, " Modal Analysis of a DFIG-Based Wind FarmInterfaced With a Series Compensated Network," IEEE TRANSACTIONS ENERGY CONVERSION, vol. 26, no. 4, pp1010 - 1020, Dec. 2011.

[18] College of Engineering, Electrical Engineering, University of Washington, Power System Test Case Archive.[Online].Available:http://www.ee.washington.edu/research/ps tcal 